\title{
Celebrating Excellence
}

\section{As we do every year, ACM convenes a gala event to celebrate and honor colleagues in our computing universe who have achieved pinnacle success in the field.}

Our most prestigious recognition is the ACM A.M. Turing Award and the 2017 award goes to John Hennessy and David Patterson:

"For pioneering a systematic, quantitative approach to the design and evaluation of computer architectures with enduring impact on the microprocessor industry."

Their primary insight was to find a method to systematically and quantitatively evaluate machine instructions for their utility and to eliminate the least used of them, replacing them with sequences of simpler instructions with faster execution times requiring lower power. In the end, their designs resulted in Reduced Instruction Set Complexity or RISC. Today, most chips make use of this form of instruction set. A complete summary of their accomplishments can be found within this issue and at the ACM Awards website. ${ }^{\mathrm{a}}$

The second most significant award from ACM is the ACM Prize in Computing and the 2017 award goes to Dina Katabi of the Massachusetts Institute of Technology's Computer Science and Artificial Intelligence Laboratory (MIT CSAIL). Her contributions to wireless communication and applications are both deep and broad. Concerned about interference in wireless networks, Katabi developed the concept of network coding in which messages are encoded and recoded as they move through network in such a way that increased resilience and capacity can be achieved. She also pioneered creative

a https://amturing.acm.org/ work on the use of Wi-Fi signals to perceive objects and life forms on the other side of walls opaque to visual frequencies. The ability to analyze these extremely weak signals seems truly straight out of science fiction! A summary of her work also can be found at the ACM Awards website. ${ }^{\mathrm{b}}$

A third recognition-the 2018-2019 Athena Lecturer Award-goes to Andrea Goldsmith of Stanford University. In addition to her contributions to the theory and practice of adaptive communications, she is also honored for her successful transfer of technology into practice. Her theories of time-varying adaptive modulation led to significant improvements in EDGE, Wi-Fi and 3GPP/LTE. She established a company-Quantenna-that developed the first adaptive Multi-in/Multi-out 4X4 antenna for 802.11N Wi-Fi applications. For more information see the ACM Awards website. ${ }^{\mathrm{c}}$

There are many more awards to be given and people to be recognized for their extraordinary accomplishments on June 23 in San Francisco. We take great pride in knowing that our colleagues continue to make significant and constructive contributions to our society. I hope that many of you will be able to join us for the celebration of their work.

Speaking of celebrations, it is fitting and timely to recognize the work of our senior leadership whose terms come to an end as these celebrations conclude. Graduating to Past Presi-

b https://awards.acm.org/acm-prize

c https://awards.acm.org/athena dent, Vicki Hanson will complete her successful two-year term as President of ACM at the end of June. Cherri Pancake will finish her term as Vice President and Elizabeth Churchill her term as Secretary-Treasurer. We owe much to all three of these dedicated women whose careers and experience have placed them in leadership roles in ACM. I have no doubt that they will continue to contribute to ACM in a variety of ways, as they have in the past. All three are important and muchneeded role models for all who work in computer science.

Artificial intelligence and, especially, machine learning, are experiencing another form of celebration as success after success is reported in diverse applications ranging from board gaming to real-time control of cloud computing cooling systems to self-driving cars. While we can take pride in the constructive aspects of these new tools of computer science, we must also be alert to the quirks, idiosyncrasies, and weaknesses of these emerging technologies. As responsible members of our profession, it is important to help policymakers and the general public to adjust their expectations of these techniques to ensure they are applied with due consideration for their limitations.

I hope to see many of you at the ACM Awards Banquet!

Vinton G. Cerf is vice president and Chief Internet Evangelist at Google. He served as ACM president from 2012-2014.

Copyright held by author 